\title{
Effect of nanoparticles on tensile, impact and fatigue properties of fibre reinforced plastics
}

\author{
R NAGALINGAM*, S SUNDARAM ${ }^{\dagger}$ and B STANLY JONES RETNAM \\ Department of Mechanical Engineering, Jayamatha Engineering College, Nagercoil 629 301, India \\ ${ }^{\dagger}$ Department of Manufacturing Engineering, Annamalai University, Annamalainagar 608 002, India
}

MS received 20 April 2009; revised 6 May 2009

\begin{abstract}
Advanced composite, fibre-reinforced polymer (FRP), has been favoured for certain aerospace, military, marine and automotive applications. Polymer nanocomposites containing layered silicates have attracted much attention. These exhibit increased modulus, decreased thermal expansion coefficient, increased solvent resistance and enhanced ionic conductivity when compared to the polymer alone. Here we have developed eight different combinations of composites FRP with nanoclay (montmorillonite) by layered manufacturing techniques (LM) and measured the mechanical properties. The measurement showed that the tensile strength, impact strength and fatigue life are greatly increased. A plausible explanation for high increase of properties has also been discussed.
\end{abstract}

Keywords. Moulding; fatigue; mechanical.

\section{Introduction}

FRPs offer numerous advantages over steel, including high strength to weight ratios, resistance to electrochemical corrosion, ease and speed of application. Research is being conducted at Queen's university in conjunction with the National Research Council (NRC) of Canada and industry partners to investigate the effects of fire on the mechanical and thermal properties of FRPs, reinforcing steel and various insulation materials used in fireproofing FRP. Small scale material tests are being conducted to characterize the mechanical and thermal properties of these materials. 'Nano technology is the understanding and control of matter at dimensions of roughly 1 to 100 nanometers, where unique phenomena enable novel applications'. The dream of a near-perfect feature will come true with these smart materials. Hence nano technology is all set to prove that there are no limits for technological developments and is going to make our life easier than before.

Building things atom by atom, molecule by molecule is nano technology. When separated, it is a 'bottom up' manufacturing approach in which machines and mechanisms are built with nanoscales, one has to manipulate atoms precisely where we wish on a structure.

Since the composite layered parts are expected to be employed in functional products, modeling of their performance under load becomes necessary. In fibre reinforced composite materials, the inherent mechanical

\footnotetext{
*Author for correspondence (nagu_7835@rediffmail.com)
}

properties of the matrix material are modified by the introduction of the reinforcing fibres. The mechanical properties of composite material depend on the material properties of the two consistent components of their interface, as well as the amount of reinforcing materials of its geometrical arrangement within the matrix. The amount of reinforcements and their arrangement are determined by the composite fabrication process (Zak et al 2000).

The mechanical properties ( $\mathrm{Yu}$ et al 2000a,b; Li and Chou 2003; Thostenson and Chou 2003) with a high aspect ratio and a high Young's modulus and tensile strength, in combination with electrical and thermal conductivity make them interesting materials for the use of nano fillers in polymers and open up new perspectives for multi functional materials, e.g. conductive polymers with improved mechanical performance.

Modification of nano $\mathrm{SiO}_{2}$ in epoxy resin based composite was more effective than that of standard $\mathrm{SiO}_{2}$ for tensile properties and impact properties due to large specific surface area and active groups on surfaces of nano$\mathrm{SiO}_{2}$ particles. Similar behaviour has been shown for the toughness of epoxy resin based composites with nano$\mathrm{SiO}_{2}$ and standard $\mathrm{SiO}_{2}$ in $\mathrm{SEM}$ images ( $\mathrm{Li}$ et al 2007).

Nano-modification of the epoxy matrix leads to novel FRPs with enhanced matrix dominated mechanical properties and an anisotropic electrical conductivity. In order to efficiently exploit the potential of nanoparticles, appropriate dispersion and sufficient amount of nano modified epoxy are required. Both requirements can be fulfilled by the application of the introduced calendaring method to manufacture the nano tube epoxy suspension 
(Hoogerbruge and Koelman 1992; Koelman et al 1993; Espafiol and Warren 1995).

Blending molten polymer and inorganic clays can result in a class of new materials, in which nanoscale clay particles, generally layered silicates, are molecularly dispersed within the polymeric matrix. Such polymerclay nanocomposites exhibit dramatic increase in several properties, including mechanical strength, heat resistance, and a decrease in gas permeability when compared to the polymeric matrix alone (Kuznetov and Balazs 2000; Fornes and Paul 2003; Fermeglia et al 2003, 2004).

The advantages offered by the fibre-reinforced polymer composites such as lightness, resistance to corrosion, resilience, translucency and greater efficiency compared with the more conventional materials, make it an obvious choice. Today, composite materials, including laminated and fibre-reinforced systems, play significant roles in many scientific and engineering realms, primarily due to their unique physical and mechanical response characteristics, such as specific strength, fracture toughness, corrosion and wear resistance (Oberoi and Goenka 2005).

Another study was conducted on the influence of silica nanoparticles on polypropylene by using two different inorganic fillers with particle size $\leq 30 \mathrm{~nm}$. As a basis for comparison, no chemically modified silica with lower bond strength between filler and polymer matrix was used. The filler dispersion state with the matrix varied from unaggregated particles to aggregates of different shape (even though silica particles were in the same diameter range). Colloidal silica nanoparticles added to polypropylene showed good dispersion of the inorganic filler into the polymer matrix, whereas the addition of powder nano silica particles showed a good dispersion of aggregates into the polypropylene as seen from the fracture surfaces. Upon addition of silica, an improvement of the elastic modulus of ca. $30 \%$ was obtained. The yield stress at this filler percentage was found in the toughness by performing Izod-impact tests. Regardless of the kind of inorganic filler, an increase in the fracture toughness of the material was obtained. An enhancement of $68 \%$ was measured with the colloidal silica particles. Some advantages of using polymers are found in their easy processing and light weight. During processing, high particle loadings result in end products with much higher weight than that of the pure polymers. Therefore, a composite with improved properties at low particle concentration is desired (Garcia et al 2004).

\section{Preparation of material}

Preparation of the moulded specimens has been done by layered manufacturing technique (LM), in the combination of nanopowder, polyester resin and emulsion fibre material of 300 micron thickness for a setting period of $12-16 \mathrm{~h}$.

\section{Test procedure}

Tensile test measures the force required to break a specimen and the extent to which the specimen stretches or elongates to that breaking point. Tensile test produces stress-displacement diagram and load-displacement diagram, which are used to determine tensile modulus. The data is often used to specify a material, to design parts to withstand application force and as a quality control check of materials. ASTM D638 specimens are placed in the grip of the Universal Testing Machine at a specified grip separation and pulled off until it failed at a test speed of $50 \mathrm{~mm} / \mathrm{min}$ for measuring strength and elongation.

Impact tests are designed to simulate the response of a material to a high rate of loading and involve a test piece being struck a sudden blow. There are two main forms of tests, the Izod and Charpy tests. Both tests involve the same type of measurement but differ in the form of the test pieces. Both involve a pendulum swinging down from a specified height $h_{0}$ to fit the test piece and fracture it. The height $h$ to which the pendulum rises after striking and breaking the test piece is a measure of the energy used in breaking. If no energy were used the pendulum would swing up to the same height $h_{0}$ it started from, i.e. the potential energy $m g h_{0}$ at the top of the pendulum swing before and after the collision would be the same. The greater the energy used in the breaking, the greater the loss of energy and so the lower the height to which the pendulum rises. If the pendulum swings up to a height $h$ after breaking the test piece then the energy used to break it is $m g h_{0}-m g h$.

Many components undergo thousands, often millions, of changes of stress. Some are repeatedly stressed and unstressed, while some undergo alternating stresses of compression and tension. For others the stress may fluctuate about some value. Many materials subject to such conditions fail, even though the maximum stress in any one stress change is less than the fracture stress determined by a simple tensile test. Such a failure, as a result of repeated stressing, is called a fatigue failure.

Fatigue tests can be carried out in a number of ways; the way used being the one needed to simulate the type of stress changes that will occur to the material of the component when in service. There are bending stress machines which bend a test piece of the material alternatively one way and then the other, torsional-fatigue machines which twist the test piece alternatively one way and then the other and another type which produces alternating tension and compression by direct stressing.

\section{Results and discussion}

Table 1 shows various combinations of polyester resin, fibre and nanopowder (montmorillonite) in wt\%. Specimens $P$ and $Q$ were prepared in combination with poly- 
ester resin and fibre only. Specimens $R, S, T, U, V$ and $W$ were prepared by optimizing the polyester resin and change the wt \% of fibre and nanopowder. These moulded specimens were prepared as per ASTM D638 and tested in computerized universal testing machine in $50 \mathrm{~mm} / \mathrm{min}$ at room temperature.

Table 1. Combination of polyester resin, fibre and nanopowder.

\begin{tabular}{|c|c|c|c|}
\hline Specimen & Combinations & $\%$ & Weight (g) \\
\hline \multirow[t]{2}{*}{$P$} & Polyester resin & 70 & 1050 \\
\hline & Fibre & 30 & 450 \\
\hline \multirow[t]{2}{*}{$Q$} & Polyester resin & 75 & 1125 \\
\hline & Fibre & 25 & 375 \\
\hline \multirow[t]{3}{*}{$R$} & Polyester resin & 70 & 1050 \\
\hline & Fibre & 28 & 420 \\
\hline & Nanopowder & 2 & 30 \\
\hline \multirow[t]{3}{*}{$S$} & Polyester resin & 70 & 1050 \\
\hline & Fibre & 26 & 390 \\
\hline & Nanopowder & 4 & 60 \\
\hline \multirow[t]{3}{*}{$T$} & Polyester resin & 70 & 1050 \\
\hline & Fibre & 25 & 375 \\
\hline & Nanopowder & 5 & 75 \\
\hline \multirow[t]{3}{*}{$U$} & Polyester resin & 70 & 1050 \\
\hline & Fibre & 24 & 360 \\
\hline & Nanopowder & 6 & 90 \\
\hline \multirow[t]{3}{*}{$V$} & Polyester resin & 70 & 1050 \\
\hline & Fibre & 22 & 330 \\
\hline & Nanopowder & 8 & 120 \\
\hline \multirow[t]{3}{*}{$W$} & Polyester resin & 70 & 1050 \\
\hline & Fibre & 20 & 300 \\
\hline & Nanopowder & 10 & 150 \\
\hline
\end{tabular}

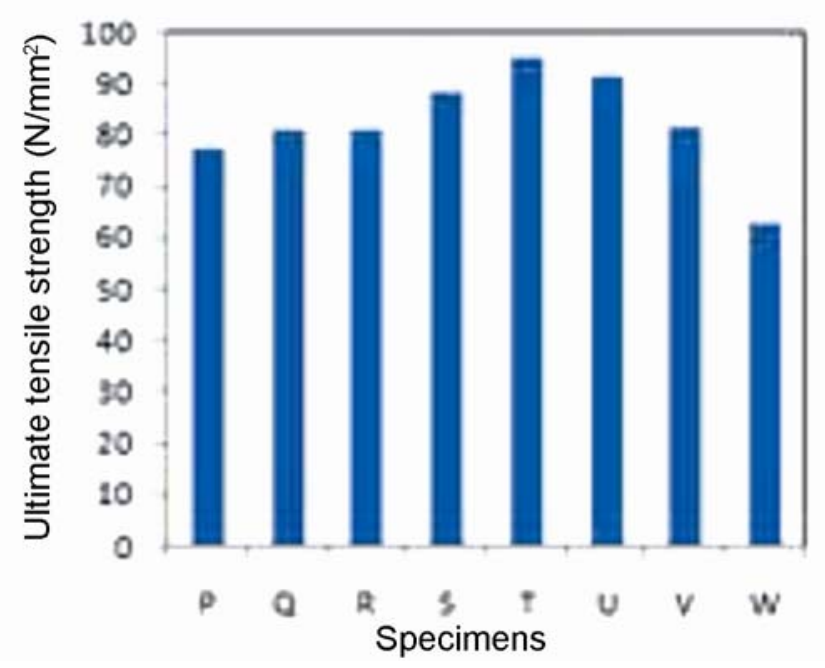

Figure 1. Ultimate tensile strength for various specimens.
Figure 1 illustrates the plots of ultimate tensile strength (UTS) in $\mathrm{N} / \mathrm{mm}^{2}$ versus specimens of various combinations. It has been seen that the specimen $P$ yielded $77.05 \mathrm{~N} / \mathrm{mm}^{2}$ for $30 \%$ of fibre, $Q$ yielded UTS of $81.04 \mathrm{~N} / \mathrm{mm}^{2}$ in reduction of $5 \mathrm{wt} \%$ of fibre, almost it increased to $5 \%$ of UTS for the reduction of $5 \%$ of fibre due to better bonding strength between fibre and polyester resin. Specimen $R$ yielded $80.65 \mathrm{~N} / \mathrm{mm}^{2}$ for the increment of $3 \%$ fibre and $2 \%$ nanopowder. Ultimate tensile strength reduced by only $0.5 \%$ due to addition of nanopowder which yielded $88.06 \mathrm{~N} / \mathrm{mm}^{2}$ for the reduction of $2 \%$ fibre and increment of $2 \%$ nanopowder. As nanopowder makes a better bonding between fibre and polyester resin, ultimate tensile strength increased to $8.5 \%$. $T$ yielded $94.65 \mathrm{~N} / \mathrm{mm}^{2}$ for the reduction of $1 \%$ fibre and increment of $1 \%$ nanopowder. Almost 7\% ultimate tensile strength increased because of the good bonding strength due to increasing of nanopowder. Specimen $U$ yielded $91.28 \mathrm{~N} / \mathrm{mm}^{2}$ for the reduction of $1 \%$ fibre and increment of nanopowder by $1 \%$. Ultimate tensile strength has been reduced to $3 \cdot 6 \%$, due to reduction of fibre specimen which can loose its strength and yielded $81.181 \mathrm{~N} / \mathrm{mm}^{2}$ for the $2 \%$ reduction of fibre and $2 \%$ increment of nanopowder. Almost it reduced by $12.4 \%$ of ultimate tensile strength due to reduction of fibre; addition of nanopowder has been reducing the bonding strength. Specimen $W$ yielded $62.47 \mathrm{~N} / \mathrm{mm}^{2}$ with a further reduction of $2 \%$ fibre and $2 \%$ increment of nanopowder. Ultimate tensile strength $(30 \%)$ has been reduced due to reduction of fibre and increment of nanopowder.

Figure 2 illustrates the plots of impact strength in $\mathrm{J} / \mathrm{mm}^{2}$ vs different specimens. For $30 \mathrm{wt} \%$ increment of fibre in specimen $P$ yielded $4 \mathrm{~J} / \mathrm{mm}^{2}$ and for reduction of $5 \mathrm{wt} \%$ of fibre, $Q$ yielded $2 \mathrm{~J} / \mathrm{mm}^{2}$. For the increment of $3 \mathrm{wt} \%$ of fibre and $2 \mathrm{wt} \%$ of nanopowder results in yield of $2 \mathrm{~J} / \mathrm{mm}^{2}$ for the specimen $R$. Specimen $S$ yields

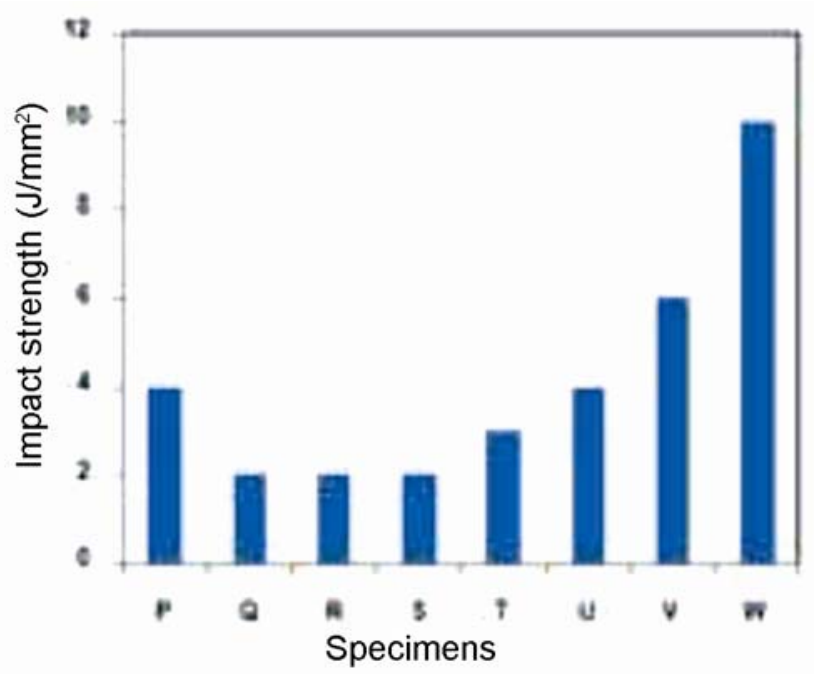

Figure 2. Impact strength for various specimens. 


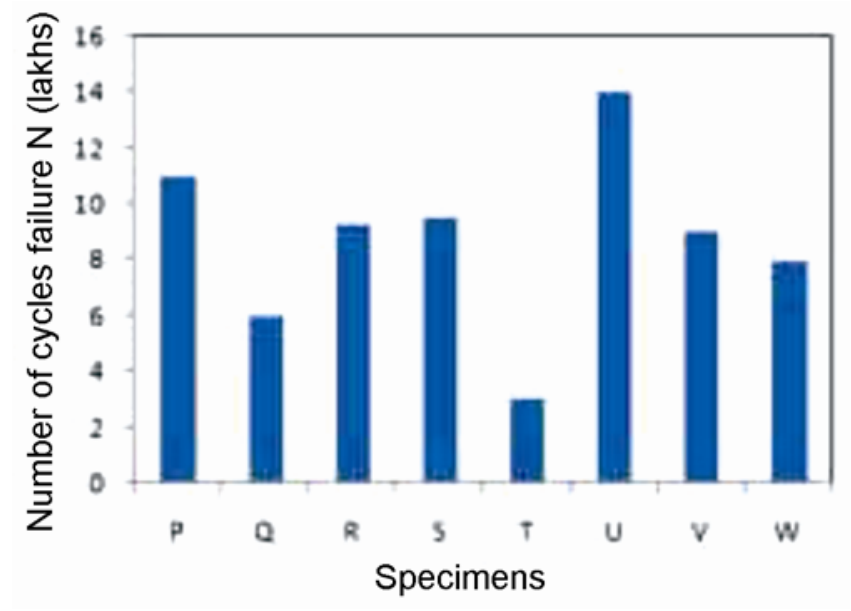

Figure 3. Fatigue life for various specimens at stress range (S) of $80 \%$ tensile strength

$2 \mathrm{~J} / \mathrm{mm}^{2}$ for $2 \mathrm{wt} \%$ reduction of fibre and $2 \mathrm{wt} \%$ increment of nanopowder. $T$ yields $3 \mathrm{~J} / \mathrm{mm}^{2}$ for $1 \mathrm{wt} \%$ reduction of fibre and $1 \mathrm{wt} \%$ increment of nanopowder. Specimen $U$ yielded $4 \mathrm{~J} / \mathrm{mm}^{2}$ for the reduction of $1 \mathrm{wt} \%$ of fibre and $1 \mathrm{wt} \%$ increment of nanopowder. Specimen $V$ yielded $6 \mathrm{~J} / \mathrm{mm}^{2}$ and $W$ yielded $10 \mathrm{~J} / \mathrm{mm}^{2}$ for $2 \mathrm{wt} \%$ reduction of fibre and increment of $2 \mathrm{wt} \%$ of nanopowder, respectively. When nanopowder is added in this fibre reinforced plastic, it increased the impact strength of material.

Figure 3 illustrates the plots of fatigue life vs different unnotched specimens in the stress range of $80 \%$ of tensile strength. For $30 \mathrm{wt} \%$ of fibre, specimen $P$ yielded $11 \times$ $10^{5}$ cycles and $Q$ yielded $6 \times 10^{5}$ cycles. For the addition of $3 \mathrm{wt} \%$ of fibre and $2 \mathrm{wt} \%$ of nanopowder yielded $9.3 \times 10^{5}$ cycles for $R$. Specimen $S$ yielded $9.5 \times$ $10^{5}$ cycles, for the increment of $2 \mathrm{wt} \%$ of nanopowder and reduction of $2 \mathrm{wt} \%$ of fibre. Further $1 \%$ increment of nanopowder in $T$ has reduced fatigue life to $3 \times$ $10^{5}$ cycles. Fatigue life greatly increased to $14 \times 10^{5}$ cycles in specimen $U$ for the increment of $1 \mathrm{wt} \%$ nanopowder and reduction of $1 \mathrm{wt} \%$ in fibre. $V$ yielded $9 \times 10^{5}$ cycles and $W$ yielded $8 \times 10^{5}$ cycles. It shows that $6 \mathrm{wt} \%$ of nanopowder and $24 \mathrm{wt} \%$ of fibre will greatly increase the fatigue life.

\section{Conclusions}

In this study, the tensile strength, impact strength and fatigue life of an experimentally produced nanocomposite fibre reinforced plastics in various combinations of polyester resin, fibre and nanopowder was investigated at room temperature. The results are summarized as follows. The nanocomposite fibre reinforced plastic has sufficiently high ultimate tensile strength and $23 \%$ improvement of ultimate tensile strength at $5 \mathrm{wt} \%$ increment of nanopowder. Impact strength increases to $10 \mathrm{~J} / \mathrm{mm}^{2}$, an addition of $10 \mathrm{wt} \%$ of nanopowder. Fatigue life increases to $14 \times 10^{5}$ cycles for the increment of $6 \mathrm{wt} \%$ of nanopowder and $24 \mathrm{wt} \%$ of fibre. The above three parameters of this study which can predict the influence of nanoparticle in FRP greatly increase tensile strength, impact strength and fatigue life.

\section{References}

Espafiol P and Warren P B 1995 Phys. Rev. E52 1734

Fermeglia M, Ferrone M and Pricel S 2003 Fluid Phase Equilib. 212315

Fermeglia M, Ferrone M and Pricel S 2004 Mol. Simul. 30289

Fornes T D and Paul D R 2003 Polymer 444993

Garcia M, Van Vliet G, Jain S, Schrauwen B A G, Sarkissov A, Van Zyl W E and Boukamp B 2004 J. Adv. Mater. Sci. 6169

Hoogerbruge P J and Koelman J M V A 1992 Europhys. Lett. 18155

Koelman J M V A and Hoogerbruge P J 1993 Europhys. Lett. 21363

Kuznetov D and Balazs A C 2000 J. Chem. Phys. 1124365

Li C and Chou T W 2003 Compos. Sci. Technol. 631571

Li Haiyan, Zhang Zhisheng, Ma Xiaofei, Hu Ming, Wang Xiuyu and Fan Panfeng 2007 Surf. Coat. Technol. 5269

Oberoi Sharad V and Goenka Akash 2005 Fibre-reinforced polymer composite structures, A review, proceedings composite (Kharagpur: Indian Institute of Technology) p. 135

Thostenson E T and Chou T W 2003 J. Phys. D36 573

Yu M F, Files B S, Arepalli S and Ruoff R S 2000a Phys. Rev. Lett. 845552

Yu M F, Lourie O, Dyer M J, Moloni K, Kelly T F and Ruoff R S 2000b Science 287637

Zak G, Haberer M, Park C B and Benhabib B 2000 Rapid Prototyping J. 6107 